Article

\title{
Water Uptake Behavior and Young Modulus Prediction of Composites Based on Treated Sisal Fibers and Poly(Lactic Acid)
}

\author{
Ander Orue, Arantxa Eceiza, Cristina Peña-Rodriguez and Aitor Arbelaiz * \\ Materials + Technologies Group, Engineering College of Gipuzkoa, \\ University of the Basque Country UPV /EHU, Donostia-San Sebastian 20018, Spain; \\ ander.orue@ehu.eus (A.O.); arantxa.eceiza@ehu.eus (A.E.); cristina.pr@ehu.eus (C.P.-R.) \\ * Correspondence: aitor.arbelaiz@ehu.eus; Tel.: +34-943-018-585 \\ Academic Editor: Jalel Labidi \\ Received: 19 February 2016; Accepted: 17 May 2016; Published: 21 May 2016
}

\begin{abstract}
The main aim of this work was to study the effect of sisal fiber surface treatments on water uptake behavior of composites based on untreated and treated fibers. For this purpose, sisal fibers were treated with different chemical treatments. All surface treatments delayed the water absorption of fibers only for a short time of period. No significant differences were observed in water uptake profiles of composites based on fibers with different surface treatments. After water uptake period, tensile strength and Young modulus values of sisal fiber/poly(lactic acid) (PLA) composites were decreased. On the other hand, composites based on $\mathrm{NaOH}+$ silane treated fibers showed the lowest diffusion coefficient values, suggesting that this treatment seemed to be the most effective treatment to reduce water diffusion rate into the composites. Finally, Young modulus values of composites, before water uptake period, were predicted using different micromechanical models and were compared with experimental data.
\end{abstract}

Keywords: lignocellulosic fiber; composites; surface modification; water uptake

\section{Introduction}

One of the main disadvantages of lignocellulosic fibers is their hydrophilic nature, which resulted in low compatibility with hydrophobic polymeric matrices during composite fabrication. Due to fiber hydrophilic character, swelling by water uptake could lead to microcracking of the composite and degradation of mechanical properties [1]. Therefore, water uptake is one of the most serious problems that prevents a wider use of lignocellulosic fiber in composites [1,2]. In a previous work [3], it was observed that the surface energy of poly(lactic acid) (PLA) was close to sisal fiber, resulting in good wettability with poly(lactic acid) matrix. Raj et al. [4] suggested that the adhesion between fiber and PLA matrix was promoted by physical interactions, such as van der Waals forces and hydrogen bonds. However, the stress transfer from PLA matrix to lignocellulosic fiber was poor [5] and several fiber surface treatments were used to improve fiber/PLA matrix interfacial adhesion [3,6-13]. For example, Rajesh et al. [14] treated sisal fibers with $10 \mathrm{wt} \% \mathrm{NaOH}$ solution followed by $\mathrm{H}_{2} \mathrm{O}_{2}$. After that, they prepared PLA/sisal fiber composites by an injection molding process. They observed that composites based on treated sisal fibers showed higher strength and modulus values than composites based on untreated fibers. They suggested that fiber/matrix interfacial adhesion was improved after fiber surface treatment. Rajesh et al. [14] also carried out water absorption measurements of composites, and they observed that the water absorption for all composites increased as a function of sisal fiber due to the hydrophilic nature of natural fibers. Furthermore, they observed that the water absorption percentage decreased in composites with successive alkali treated sisal fiber. They reported that after 
alkali treatment sisal fibers became more hydrophobic. Jiang et al. [15] treated sisal fibers with $10 \mathrm{wt} \%$ $\mathrm{NaOH}$ solution, and they prepared treated sisal fiber/PLA composites by compression molding. They observed that composites based on treated sisal fibers did not offer good mechanical properties as a result of a poor fiber/matrix interfacial adhesion and an inadequate dispersion of fibers in PLA matrix.

The main highlights of this work compared to the previous paper are the water uptake behavior of the PLA/sisal composites and its effect on composites tensile properties as well as the use of different models to predict the tensile modulus. In the present study, sisal fibers were treated with alkali, silane and combination of both treatments. The effect of surface treatments on water uptake behavior of composites based on PLA matrix and untreated and treated fibers were carried out. The diffusion coefficients of composites were determined and the effects of water uptake on the mechanical properties of composites were studied. Moreover, the morphology of fractured surface of composites after water uptake period was observed by scanning electron microscopy (SEM). On the other hand, different micromechanical models were used to predict the Young modulus values of sisal fiber/PLA composites before the water uptake period, and obtained theoretical values were compared with the experimental data.

\section{Experimental}

\subsection{Materials}

PLA (IngeoTM, 2003D) provided by NatureWorks LLC (Minnetonka, MN, USA) was used as a matrix. According to the supplier, the D-isomer content of the PLA was 4\%, with a melt flow index of $6 \mathrm{~g} / 10 \mathrm{~min}$ at $210^{\circ} \mathrm{C}$ and a density of $1.24 \mathrm{~g} / \mathrm{cm}^{3}$. The melting temperature range of this PLA is $145-160^{\circ} \mathrm{C}$. Sisal fibers used in this work were kindly supplied by Celulosa de Levante S.A. (Tortosa, Spain). The chemical composition of untreated and treated sisal fibers was studied in a previous work [3]. Fibers were chopped to a length of approximately $40 \mathrm{~mm}$ and the diameter values varied from 100 to $200 \mu \mathrm{m}$. Sodium hydroxide pellets, supplied by Panreac (Castellar del Vallés, Spain), and 3-(2-aminoethyl amino) propyltrimethoxy silane, supplied by Sigma Aldrich (San Luis, AZ, USA) were used as fiber surface modifiers. Other reagents employed were glacial acetic acid supplied by Panreac.

\subsection{Fiber Surface Treatments}

All fiber surface treatments were carried out following the conditions described in previous works [3,5]. For alkali treatment, sisal fibers were pre-treated with $2 \mathrm{wt} \% \mathrm{NaOH}$ solution and after this, fibers were treated with $7.5 \mathrm{wt} \% \mathrm{NaOH}$ solution under reflux. Silane treatment was carried out soaking sisal fibers in 3-(2-aminoethyl amino) propyltrimethoxy silane aqueous solution (2\% v/v) under continuous stirring for $3 \mathrm{~h}$. Then, wet fibers were kept in air for three days before drying at $100{ }^{\circ} \mathrm{C}$. Finally, when a combination of both treatments was applied to sisal fibers, alkali treated fibers were further modified by the silane chemical agents. The same conditions described previously for alkali and silane treatment were used.

\subsection{Compounding and Processing of Composites}

Compounding and processing conditions of composites were the same as used in the previous work [5]. Briefly, compounding was carried out in a melt mixer HAAKE Rheomix 600 (Thermo Scientific, Karlsruhe, Germany) with two Banbury rotors, and a mixing temperature of $185{ }^{\circ} \mathrm{C}$ was selected. The loading of sisal fibers varied from $20 \mathrm{wt} \%$ to $40 \mathrm{wt} \%$. After the mixture was pelletized, the molding of pellets was carried out in a HAAKE Minijet II (Thermo Scientific, Karlsruhe, Germany) injection machine and dog bone specimens (ASTM-D-638-10 type V) were molded. Figure 1 shows tensile specimens obtained after injection process and the set-up machine used in the work. 


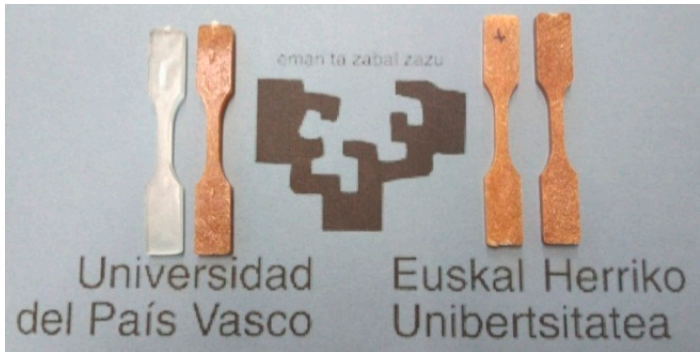

(a)

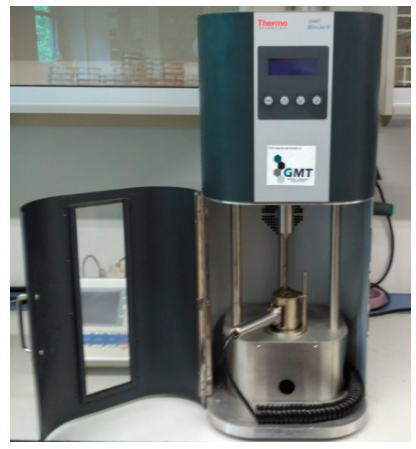

(b)

Figure 1. (a) Image of tensile specimens obtained after injection process; and (b) set-up machine used.

\subsection{Contact Angle Measurements}

Contact angle values of neat PLA matrix and untreated and treated sisal fibers were measured with OCA 20 (Data Physics Instruments, Filderstadt, Germany) using HPLC water as test liquid. A controlled amount of sisal fiber was compressed in a mold to obtain disc geometry and a water droplet was deposited on the surface. Images were recorded as soon as the droplet was deposited on the surface and also every two seconds until the droplet was totally absorbed.

\subsection{Water Uptake}

In order to study the water uptake process, $63.5 \mathrm{~mm}$ length dog bone specimens with a narrow section of $3.18 \times 3.29 \mathrm{~mm}^{2}$ were immersed in distilled water at $28^{\circ} \mathrm{C}$. Weight gain due to absorbed water was periodically measured taking samples out from water. Before weighing, the wet surface of the sample was quickly dried, weighed and then samples were again immersed in water. This process continued during 209 days and the water uptake at time $t$ was calculated using Equation (1) [1]:

$$
\Delta m(t)=\left(\frac{w_{t}-w_{0}}{w_{0}}\right) \times 100
$$

where $w_{0}$ is the initial weight of specimen and $w_{t}$ is the weight of wet specimen at time $t$.

Diffusivity was analyzed with the hypothesis of a Fickian mechanism. A one-dimensional approach was followed for the determination of the diffusion coefficient, $D$, which can be calculated from Equation (2) [1,16]:

$$
D=\pi\left(\frac{d \theta}{4 \Delta m(\infty)}\right)^{2}
$$

where $\theta$ is the slope of the linear portion of the sorption curves, $\Delta m(\infty)$ is equilibrium water uptake value and $d$ the initial sample thickness. The specimens used to determine the diffusion coefficient were normally of finite dimensions, and a correction for the effect of diffusion through the edges can be made according to Equation (3) for rectangular specimens:

$$
D_{\mathrm{c}}=D\left(1+\frac{d}{h}+\frac{d}{w}\right)^{-2}
$$

where $D_{\mathrm{c}}$ is the corrected diffusion coefficient and $h$ and $w$ are sample length and width, respectively. This equation is based on the assumption that the diffusion rates are the same in all directions [17]. Although tensile samples are not rectangular because they have grips that lead to water absorption, for simplicity, tensile specimens were considered as rectangular with 9.53 and $63.5 \mathrm{~mm}$ width and length, respectively. 


\subsubsection{Mechanical Properties of Composites}

Tensile tests of PLA and composites were performed using Insight 10 (MTS Company, Eden Prairie, MI, USA) with a load cell of $10 \mathrm{kN}$ with accuracy of $0.5 \%$ and at $5 \mathrm{~mm} / \mathrm{min}$ deformation rate. Tensile strength, strain at break, and Young modulus (using the video extensometer) values of composites before and after the water uptake period were determined.

\subsubsection{Scanning Electron Microscopy}

SEM was used to analyze the fracture surfaces of neat PLA polymer and composites based on untreated and treated sisal fibers after water uptake period. SEM micrographs were performed by JSM-6400 (JEOL, Tokyo, Japan) equipment with a wolframiun filament operating at an accelerated voltage of $10 \mathrm{kV}$. All samples were coated with chromium using a Quorum Q150 TES metallizer (Ashford, UK).

\subsection{Analysis of Young Modulus}

The Young modulus of short fiber reinforced thermoplastics can be experimentally determined or estimated using different micromechanical models. Micromechanical models are based among other issues on the individual components properties of composite, such as elastic modulus of fiber $\left(E_{\mathrm{f}}\right)$ and matrix $\left(E_{\mathrm{m}}\right)$; the relative volume fraction of fiber $\left(\varnothing_{f}\right)$ and matrix $\left(\varnothing_{m}\right)$; length $(l)$, diameter $(d)$ and aspect ratio $(l / d)$ values of fibers [18]. Volume fractions were determined from the weight fractions and the densities of each component measured in the previous work [5]. There are a wide variety of theoretical models to predict the elastic properties of filler reinforced composites. In this study, Hill [19] (Equation (4)), Halpin-Tsai [20] (Equation (7)) and shear-lag [21] (Equation (12)) equations were used.

\subsubsection{Hill Equation}

$$
E_{\mathrm{C}}=\frac{E_{\mathrm{L}}+E_{\mathrm{T}}}{2}
$$

where $E_{\mathrm{L}}$ and $E_{\mathrm{T}}$ are longitudinal and transverse moduli:

$$
\begin{aligned}
& E_{\mathrm{L}}=E_{\mathrm{f}} \varnothing_{\mathrm{f}}+E_{\mathrm{m}} \varnothing_{\mathrm{m}} \\
& E_{\mathrm{T}}=\frac{E_{\mathrm{f}} E_{\mathrm{m}}}{E_{\mathrm{m}} \varnothing_{\mathrm{f}}+E_{\mathrm{f}} \varnothing_{\mathrm{m}}}
\end{aligned}
$$

2.6.2. Halpin-Tsai Equation

$$
E_{\mathrm{c}}=\frac{3}{8} E_{\mathrm{L}}+\frac{5}{8} E_{\mathrm{T}}
$$

In this case, longitudinal $\left(E_{\mathrm{L}}\right)$ and transverse $\left(E_{\mathrm{T}}\right)$ moduli are given by Equations (8) and (9):

$$
\begin{gathered}
E_{\mathrm{L}}=E_{\mathrm{m}}\left[\frac{1+2(l / d) \eta_{\mathrm{L}} \varnothing_{\mathrm{f}}}{1-\eta_{\mathrm{L}} \varnothing_{\mathrm{f}}}\right] \\
E_{\mathrm{T}}=E_{\mathrm{m}}\left(\frac{1+2 \eta_{\mathrm{T}} \varnothing_{\mathrm{f}}}{1-\eta_{\mathrm{T}} \varnothing_{\mathrm{f}}}\right)
\end{gathered}
$$

The constants $\eta_{\mathrm{L}}$ and $\eta_{\mathrm{T}}$ take the following expression (Equations (10) and (11)):

$$
\eta_{\mathrm{L}}=\frac{\left(E_{\mathrm{f}} / E_{\mathrm{m}}\right)-1}{\left(E_{\mathrm{f}} / E_{\mathrm{m}}\right)+(2 l / d)}
$$




$$
\eta_{\mathrm{T}}=\frac{\left(E_{\mathrm{f}} / E_{\mathrm{m}}\right)-1}{\left(E_{\mathrm{f}} / E_{\mathrm{m}}\right)+2}
$$

where $l$ and $d$ refer to the length and diameter of the fiber after processing, respectively.

2.6.3. Shear-Lag Analysis

$$
E_{\mathrm{c}}=E_{\mathrm{f}}\left(1-\frac{\tanh \left(\frac{\eta l}{2}\right)}{\frac{\eta l}{2}}\right) \varnothing_{\mathrm{f}}+E_{\mathrm{m}}\left(1-\varnothing_{\mathrm{f}}\right)
$$

In Equation (12), the shear-lag parameter ( $\eta$ ) derived by Nairn [22] is given by the following equation (Equation (13)):

$$
\eta=\left\{\frac{2}{r_{\mathrm{f}}^{2} E_{\mathrm{f}} E_{\mathrm{m}}}\left\{\frac{E_{\mathrm{f}} \varnothing_{\mathrm{f}}+E_{\mathrm{m}}\left(1-\varnothing_{\mathrm{f}}\right)}{\frac{\left(1-\varnothing_{\mathrm{f}}\right)}{4 G_{\mathrm{f}}}+\frac{1}{2 G_{\mathrm{m}}}\left[\frac{1}{\left(1-\varnothing_{\mathrm{f}}\right)} \ln \left(\frac{1}{\varnothing_{\mathrm{f}}}\right)-1-\frac{\left(1-\varnothing_{\mathrm{f}}\right)}{2}\right]}\right\}\right\}^{1 / 2}
$$

where $l$ and $r_{\mathrm{f}}$ are the length and radius of sisal fibers after processing, and $G_{\mathrm{f}}$ and $G_{\mathrm{m}}$ refers to shear modulus of the fiber and matrix, respectively. The values used for $G_{\mathrm{f}}$ and $G_{\mathrm{m}}$ were 1.10 and $1.29 \mathrm{GPa}$, respectively $[23,24]$.

\section{Results and Discussion}

\subsection{Contact Angle and Water Drop Absorption}

Figure 2 shows the contact angle values and the absorption of a water drop in neat PLA sample surface and in compressed disc geometry surfaces of sisal fibers. As reported in a previous work, the silane treatment increased the hydrophobic character of sisal fibers resulting in the highest contact angle value [3]. However, obtained images showed that all fiber surface treatments delayed the water absorption only for a short time period. After $10 \mathrm{~s}$, the water drop was completely absorbed by untreated and treated sisal fibers. Although the fiber surface was modified after chemical treatments, possibly the water could penetrate through the internal porous structure, called the lumen, being probably the main reason for absorbing water [25].

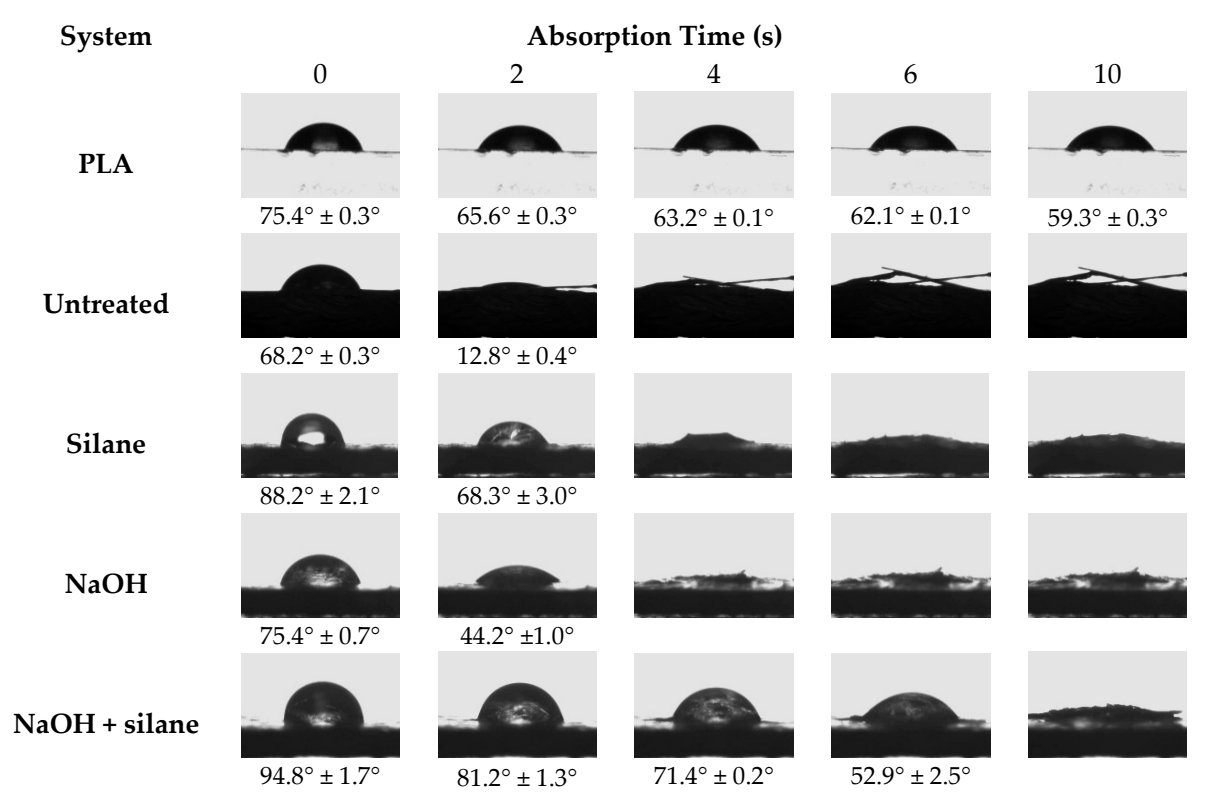

Figure 2. Contact angle values and the absorption of a water drop in neat poly(lactic acid) sample surface and in compressed disc geometry surfaces of sisal fibers at different intervals of time. 


\subsection{Water Uptake of Composites}

One serious handicap related to the use of lignocellulosic fibers in composite materials is their sensitivity to water, which can reduce dramatically composite mechanical performances $[1,11]$. The evolution of the water absorption profiles as a function of square root of immersion time for different chemical treatments and fiber contents is showed in Figure 3a-c. In all samples, an initial linear relationship between water uptake and square root of time is observed, followed by plateau saturation, indicating a typical Fickian behavior. Due to moderate polarity induced by the presence of ester bonds $[3,26]$, PLA absorbs higher water content $(1.1 \%)$ than other polymers such as polypropylene (PP) or polyethylene (PE) [1,27]. The incorporation of untreated and treated sisal fibers into the PLA matrix clearly led to an increment in the water uptake values due to the higher hydrophilic character of lignocellulosic fibers. The water uptake at saturation values of composites increased with increasing the fiber content in the composite. Significant differences were not observed in water uptake profiles of composites based on fibers with different surface treatments. Zou et al. [8] studied the effect of different surface treatments on water absorption for composites based on PLA with $10 \mathrm{wt} \%$ of short sisal fiber. They treated sisal fibers with an alkali solution and with a combination of $\mathrm{NaOH}+$ silane chemical agent, where the used silane chemical agent was $\gamma$-amine propyltriehoxysilane. They observed that the water absorption of composites based on alkali treated fibers was similar to composites based on untreated fibers. However, in contrast to results obtained in this work, they also reported that the absorption of composites based on $\mathrm{NaOH}+$ silane fibers reduced about $22 \%$ compared to untreated fiber ones. A possible explanation not to observe this reduction in water uptake period of composites based on $\mathrm{NaOH}+$ silane treated fibers could be that the silane chemical agent and the treatment conditions used in this work were not the same. Zou et al. [8] soaked sisal fibers in $5 \% w / v \gamma$-amine propyltriehoxysilane ethanol solution for $2 \mathrm{~h}$, whereas, in this work, untreated and alkali treated sisal fiber were soaked in 3-(2-aminoethyl amino) propyltrimethoxy silane water solution for $3 \mathrm{~h}$.

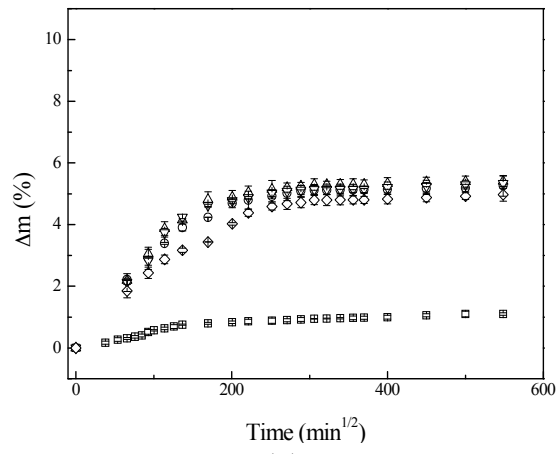

(a)

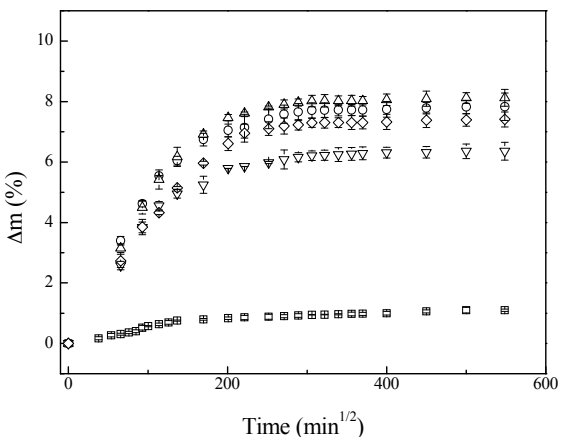

(b)

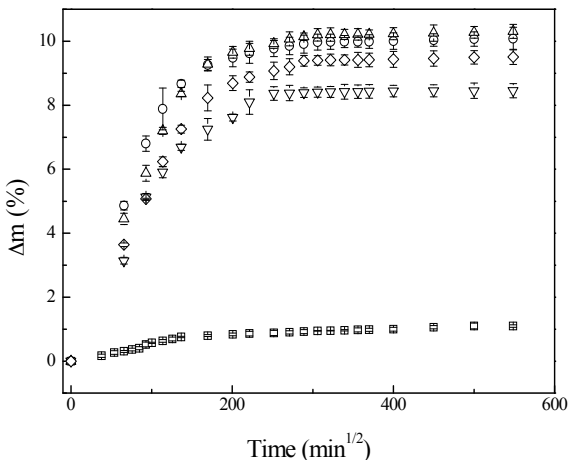

(c)

Figure 3. Water uptake profiles for composites as a function of square root of immersion time for different fiber surface treatments and fiber content: (a) $20 \mathrm{wt} \%$; (b) $30 \mathrm{wt} \%$; and (c) $40 \mathrm{wt} \%$. $(\square)$ Poly(lactic acid), (॰) Untreated, $(\Delta)$ Silane, $(\nabla) \mathrm{NaOH}$ and $(\diamond) \mathrm{NaOH}+$ silane. 
The experimentally determined parameters used in the calculations, including the initial linear slope of the sorption curve, $\theta$, and equilibrium water uptake values, $\Delta m(\infty)$, are given in Table 1 . The Fickian diffusion coefficient values of neat PLA matrix and composites with different fiber surface treatments and fiber content are also showed in Table 1. The equilibrium water uptake value of PLA matrix was small and the diffusion coefficient and corrected diffusion coefficient values of $6.7 \times 10^{-9} \mathrm{~cm}^{2} / \mathrm{s}$ and $3.4 \times 10^{-9} \mathrm{~cm}^{2} / \mathrm{s}$ were calculated, respectively. Obtained values are in agreement with those values published in the literature [28-30]. Yew et al. [28] immersed PLA samples in water at $30{ }^{\circ} \mathrm{C}$ for 30 days and they reported a diffusion coefficient value of $5.6 \times 10^{-9} \mathrm{~cm}^{2} / \mathrm{s}$. Deroine et al. [29] calculated a diffusion coefficient value of $48 \times 10^{-9} \mathrm{~cm}^{2} / \mathrm{s}$ for PLA immersed in distilled water at $25^{\circ} \mathrm{C}$.

Table 1. Fiber volume fraction $\left(\varnothing_{f}\right)$, initial linear slope $(\theta)$, equilibrium water uptake $(\Delta m(\infty))$, diffusion coefficient $(D)$ and corrected diffusion coefficient $\left(D_{\mathrm{c}}\right)$ values for poly(lactic acid) matrix and composites.

\begin{tabular}{|c|c|c|c|c|c|}
\hline Sample & $\varnothing_{f}$ & $\theta\left(\% / \min ^{1 / 2}\right)$ & $\Delta m(\infty)(\%)$ & $D \times 10^{-9}\left(\mathrm{~cm}^{2} / \mathrm{s}\right)$ & $D_{\mathrm{c}} \times 10^{-9}\left(\mathrm{~cm}^{2} / \mathrm{s}\right)$ \\
\hline PLA & 0 & 0.00479 & 1.10 & 6.7 & 3.4 \\
\hline \multirow{3}{*}{ Untreated } & 0.156 & 0.02869 & 5.26 & 10.5 & 5.4 \\
\hline & 0.254 & 0.04547 & 7.83 & 11.9 & 6.1 \\
\hline & 0.382 & 0.06518 & 10.08 & 14.8 & 7.6 \\
\hline \multirow{3}{*}{ Silane } & 0.152 & 0.03150 & 5.41 & 12.0 & 6.2 \\
\hline & 0.248 & 0.04595 & 8.12 & 11.3 & 5.8 \\
\hline & 0.375 & 0.06135 & 10.31 & 12.5 & 6.4 \\
\hline \multirow{3}{*}{$\mathrm{NaOH}$} & 0.171 & 0.03143 & 5.33 & 12.3 & 6.3 \\
\hline & 0.236 & 0.03761 & 6.26 & 12.4 & 6.4 \\
\hline & 0.341 & 0.05057 & 8.87 & 12.7 & 6.5 \\
\hline \multirow{3}{*}{$\begin{array}{l}\mathrm{NaOH}+ \\
\text { silane }\end{array}$} & 0.174 & 0.02364 & 4.97 & 8.0 & 4.1 \\
\hline & 0.239 & 0.03768 & 7.41 & 9.2 & 4.7 \\
\hline & 0.345 & 0.05352 & 9.51 & 11.2 & 5.7 \\
\hline
\end{tabular}

It was observed that increasing fiber loading in composite led to higher diffusion coefficient values. Due to the hydrophilic character of natural fibers, the inclusion of water molecules inside the composite materials was favored as demonstrated by the rate of the diffusion processes [31]. Yew et al. [28] prepared composites of PLA with $20 \mathrm{wt} \%$ rice starch and immersed them in water at $30{ }^{\circ} \mathrm{C}$ for 30 days. They observed that after adding rice starch to neat PLA, the diffusion coefficient value increased from $5.6 \times 10^{-6} \mathrm{~cm}^{2} / \mathrm{s}$ to $6.9 \times 10^{-9} \mathrm{~cm}^{2} / \mathrm{s}$. Le Duigou et al. [30] prepared PLA composites with $20 \mathrm{wt} \%$ of flax fiber and immersed in seawater for two years. They observed that the corrected diffusion coefficient of PLA increased after the addition of flax fiber. Comparing different fiber surface treatments used, it was observed that the diffusion coefficient of composites based on $\mathrm{NaOH}+$ silane treated sisal fibers was reduced considerably, suggesting that this treatment seemed to be the most effective treatment to reduce water diffusion rate into the composites.

\section{Effect of Water Uptake on Mechanical Properties}

Table 2 shows the tensile strength $\left(\sigma_{t}\right)$, Young modulus $\left(E_{t}\right)$ and deformation at break $\left(\varepsilon_{\mathfrak{b}}\right)$ values of composites based on untreated and treated sisal fibers before and after water uptake period, respectively. After the immersion in distilled water at $28{ }^{\circ} \mathrm{C}$ for 209 days, tensile strength and Young modulus values decreased, probably because water molecules would change the structure and properties of the fibers, matrix and the interface between them. On the other hand, after the water absorption process, the values of deformation at break increased. Probably, water molecules acted as a plasticizer agent in composite material, leading to an increment of the maximum strain [32]. The decrease of tensile strength and Young modulus values after water uptake period was also reported by other authors for composites based on lignocellulosic fibers and polymeric matrices $[1,33]$. Islam et al. [33] studied the influence of hydrothermal ageing on mechanical properties of composites 
based on PLA with untreated and alkali treated hemp fibers. They observed a reduction in tensile strength and Young modulus values after samples were immersed in distilled water at 25 and $50{ }^{\circ} \mathrm{C}$ for three months. When fiber/matrix interface is accessible to moisture from the environment, the cellulosic fibers tend to swell, favoring the ultimate debonding of the fibers and resulting in a reduction in composites' tensile strength values [16]. Moreover, hydrothermal ageing may also lead to the degradation of natural fibers and PLA matrix by hydrolytic mechanism. Consequently, water absorption and its resulting effects could contribute to the loss of the fiber/matrix adhesion, weakening the interface adhesion and also deteriorating the mechanical properties of fibers and PLA matrix [31].

Table 2. Tensile properties of poly(lactic acid) matrix and composites based on sisal fibers before and after water uptake period.

\begin{tabular}{cccccccc}
\hline \multirow{2}{*}{ Sample } & \multicolumn{3}{c}{ Before Water Uptake Period } & \multicolumn{3}{c}{ After Water Uptake Period } \\
\cline { 2 - 7 } & $\boldsymbol{\varnothing}_{f}$ & $\boldsymbol{\sigma}_{\mathbf{t}}(\mathbf{M P a})$ & $\boldsymbol{E}_{\mathbf{t}}(\mathrm{GPa})$ & $\boldsymbol{\varepsilon}_{\mathbf{b}} \mathbf{( \% )}$ & $\boldsymbol{\sigma}_{\mathbf{t}}(\mathbf{M P a})$ & $\boldsymbol{E}_{\mathbf{t}}(\mathrm{GPa})$ & $\boldsymbol{\varepsilon}_{\mathbf{b}} \mathbf{( \% )}$ \\
\hline PLA & 0 & $66.1 \pm 1.7$ & $3.9 \pm 0.5$ & $2.4 \pm 0.3$ & $62.9 \pm 1.5$ & $3.5 \pm 0.3$ & $2.8 \pm 0.1$ \\
\hline \multirow{3}{*}{ Untreated } & 0.156 & $53.8 \pm 0.9$ & $5.5 \pm 0.9$ & $1.8 \pm 0.4$ & $48.1 \pm 1.6$ & $3.2 \pm 0.4$ & $3.1 \pm 0.1$ \\
& 0.254 & $47.3 \pm 1.7$ & $5.9 \pm 0.7$ & $1.1 \pm 0.3$ & $40.4 \pm 1.8$ & $4.0 \pm 0.1$ & $2.2 \pm 0.1$ \\
& 0.382 & $39.3 \pm 3.4$ & $6.4 \pm 1.0$ & $0.8 \pm 0.1$ & $35.6 \pm 1.4$ & $1.5 \pm 0.2$ & $2.2 \pm 0.1$ \\
\hline \multirow{3}{*}{ Silane } & 0.152 & $57.6 \pm 2.9$ & $4.4 \pm 0.7$ & $1.9 \pm 0.3$ & $33.8 \pm 2.2$ & $2.8 \pm 0.3$ & $2.5 \pm 0.1$ \\
& 0.248 & $59.9 \pm 1.5$ & $6.4 \pm 0.7$ & $1,5 \pm 0.3$ & $34.5 \pm 2.0$ & $2.7 \pm 0.1$ & $1.9 \pm 0.1$ \\
& 0.375 & $61.8 \pm 3.1$ & $7.5 \pm 0.6$ & $1.0 \pm 0.2$ & $32.0 \pm 1.9$ & $1.6 \pm 0.2$ & $1.6 \pm 0.2$ \\
\hline \multirow{3}{*}{$\mathrm{NaOH}$} & 0.171 & $66.1 \pm 3.2$ & $6.5 \pm 0.4$ & $1.6 \pm 0.3$ & $45.4 \pm 1.0$ & $3.3 \pm 0.2$ & $2.4 \pm 0.3$ \\
& 0.236 & $74.8 \pm 3.5$ & $7.2 \pm 0.7$ & $1.5 \pm 0.1$ & $35.1 \pm 0.4$ & $3.0 \pm 0.2$ & $2.3 \pm 0.3$ \\
& 0.341 & $81.5 \pm 1.4$ & $8.1 \pm 0.8$ & $1.4 \pm 0.1$ & $31.9 \pm 1.3$ & $2.1 \pm 0.5$ & $2.4 \pm 0.1$ \\
\hline \multirow{3}{*}{$\mathrm{NaOH}+$ silane } & 0.174 & $66.9 \pm 1.0$ & $5.9 \pm 0.4$ & $1.8 \pm 0.2$ & $42.3 \pm 0.9$ & $3.5 \pm 0.1$ & $3.2 \pm 0.3$ \\
& 0.239 & $74.7 \pm 1.4$ & $6.9 \pm 0.9$ & $1.5 \pm 0.1$ & $38.0 \pm 1.3$ & $2.9 \pm 0.2$ & $2.0 \pm 0.2$ \\
& 0.345 & $78.6 \pm 3.5$ & $8.3 \pm 0.5$ & $1.4 \pm 0.2$ & $34.9 \pm 2.0$ & $2.7 \pm 0.3$ & $1.9 \pm 0.2$ \\
\hline
\end{tabular}

The percentage variations of the tensile properties of studied systems after immersion in water are shown in Table 3. Taking into account the experimental results reported in Tables 2 and 3 it was evident that the chemical treatments did not have noticeable effects on the retention of the mechanical properties.

Table 3. Percentage variations of the tensile properties of studied systems after immersion in water.

\begin{tabular}{ccccc}
\hline Sample & $\varnothing_{f}$ & $\Delta \sigma_{\mathbf{t}}(\mathbf{M P a})$ & $\Delta \boldsymbol{E}_{\mathbf{t}}(\mathbf{G P a})$ & $\Delta \varepsilon_{\mathbf{b}}(\mathbf{\%})$ \\
\hline PLA & 0 & -5 & -10 & +17 \\
\hline \multirow{3}{*}{ Untreated } & 0.156 & -11 & -42 & +72 \\
& 0.254 & -15 & -32 & +100 \\
& 0.382 & -9 & -77 & +175 \\
\hline \multirow{2}{*}{ Silane } & 0.152 & -41 & -36 & +32 \\
& 0.248 & -42 & -58 & +27 \\
& 0.375 & -48 & -79 & +60 \\
\hline \multirow{2}{*}{$\mathrm{NaOH}$} & 0.171 & -31 & -49 & +50 \\
& 0.236 & -53 & -58 & +53 \\
\hline \multirow{2}{*}{$\mathrm{NaOH}+$ silane } & 0.341 & -61 & -74 & +71 \\
& 0.174 & -37 & -41 & +78 \\
& 0.239 & -49 & -58 & +33 \\
\hline
\end{tabular}

In the previous work [5], SEM micrographs of composites before the water uptake period showed a homogeneous dispersion of sisal fibers in the PLA matrix. However, especially in composites based on untreated fibers and to a lesser extent in composites based on silane treated fibers, pulled-out fibers 
and holes were observed. On the other hand, pulled-out fibers could hardly be observed in SEM micrographs of alkali and $\mathrm{NaOH}+$ silane treated fibers, suggesting that sisal fibers were coated with polymer, and, consequently, fiber/PLA adhesion were improved. SEM micrographs of composites after the water uptake period are showed in Figure $4 \mathrm{a}-\mathrm{d}$. The micrographs showed that the dispersion of sisal fibers was homogenous in the PLA matrix. Moreover, it was observed that the sisal fibers were randomly oriented in the matrix. However, in all systems, pulled-out fibers and holes can be observed, suggesting that water seemed to damage the adhesion between the PLA matrix and sisal fibers. Fiber/PLA poor adhesion caused either an inefficient stress transfer from matrix to fiber, worsening composites' mechanical properties, and also an easy penetration and storage of water. Therefore, all studied composites showed similar water absorption profiles.

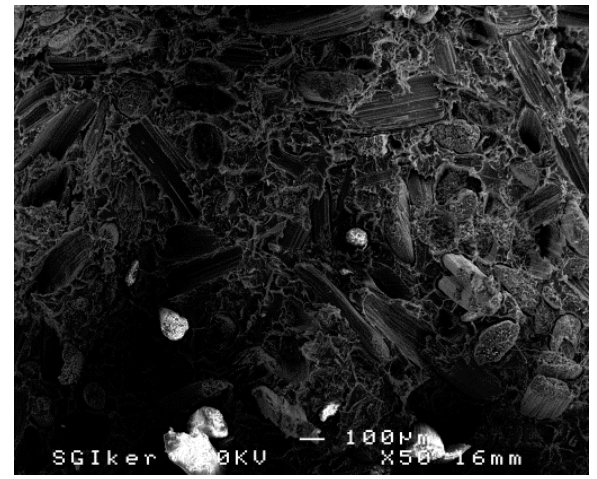

(a)

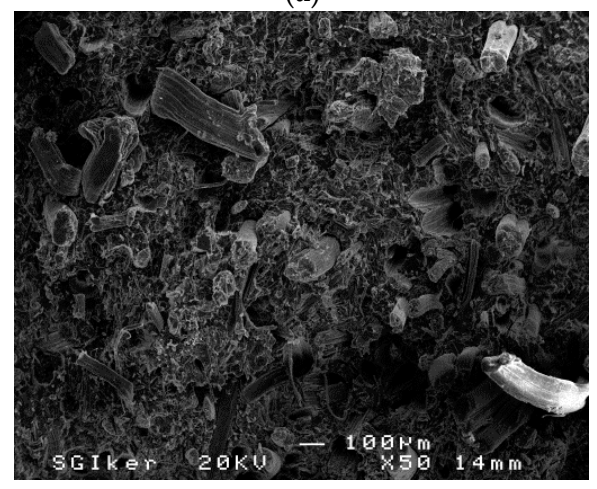

(c)

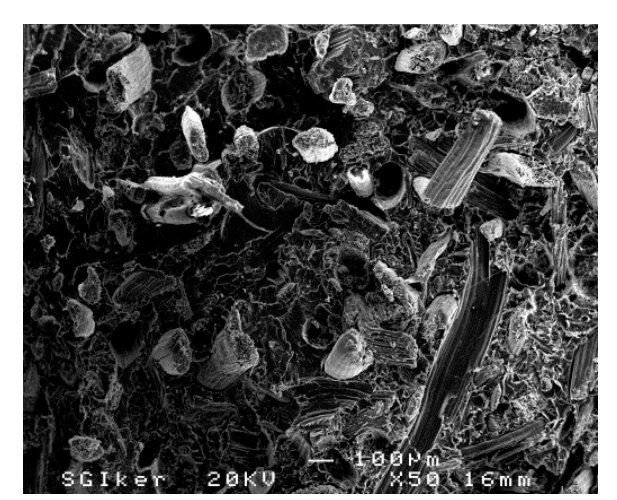

(b)

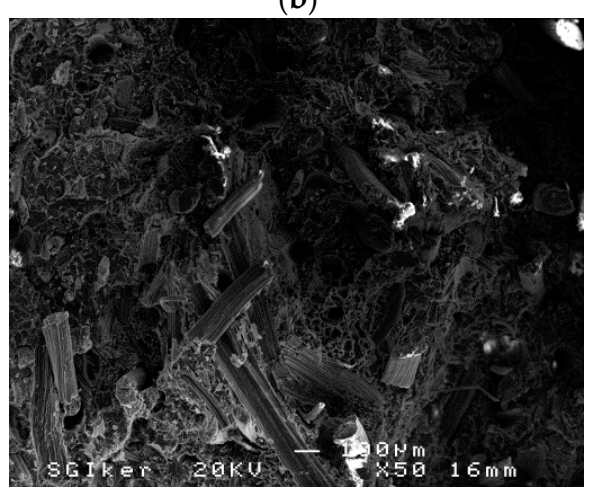

(d)

Figure 4. SEM micrographs of PLA/sisal composites (30 wt \%) after water uptake period: (a) untreated; (b) silane; (c) $\mathrm{NaOH}$; and (d) $\mathrm{NaOH}+$ silane.

\subsection{Young Modulus Prediction}

Table 4 shows the mean length, diameter and aspect ratio values of sisal fibers after processing. Moreover, $E_{\mathrm{m}}$ and $E_{\mathrm{f}}$ values of untreated and treated sisal fibers obtained in the previous works are given in Table 4 [3,5]. All of these values were used to predict the Young modulus values of PLA/sisal fiber composites.

Table 4. Mean length, diameter, aspect ratio $(l / d)$, extrapolated and experimental Young modulus values of untreated and treated sisal fibers used for predicting composites Young modulus.

\begin{tabular}{cccccc}
\hline Fiber & Length $(\boldsymbol{\mu m})$ & $\begin{array}{c}\text { Diameter } \\
(\boldsymbol{\mu} \mathbf{m})\end{array}$ & $l / d$ & $\begin{array}{c}E_{\mathbf{f}} \text { (Experimental) } \\
(\mathbf{G P a})\end{array}$ & $\begin{array}{c}E_{\mathrm{f}} \text { (Extrapolated) } \\
(\mathbf{G P a})\end{array}$ \\
\hline Untreated & 513 & 130 & 3.9 & 11.1 & 11.2 \\
Silane & 571 & 104 & 5.5 & 10.3 & 13.8 \\
$\mathrm{NaOH}$ & 543 & 94 & 5.8 & 7.8 & 17.0 \\
$\mathrm{NaOH}+$ silane & 555 & 84 & 6.6 & 7.1 & 16.5 \\
\hline
\end{tabular}


Figure 5a-d compares the theoretical and experimental tensile modulus values of composites based on untreated and treated sisal fibers. It was observed that the experimental tensile modulus of composites increased linearly as the content of fiber was increased [5].

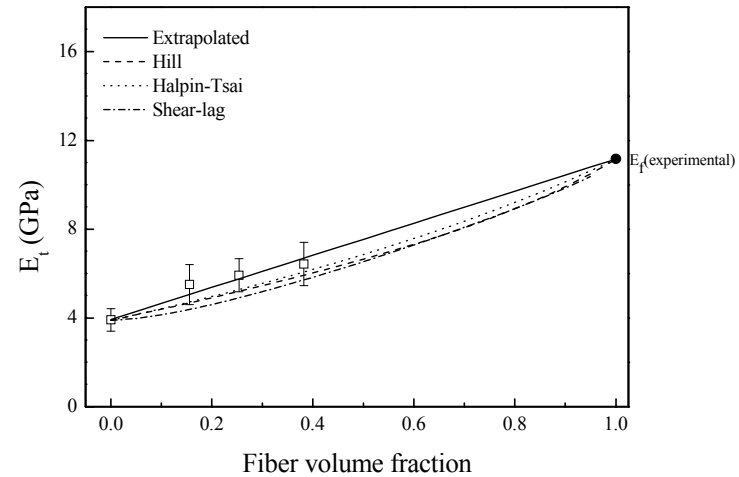

(a)

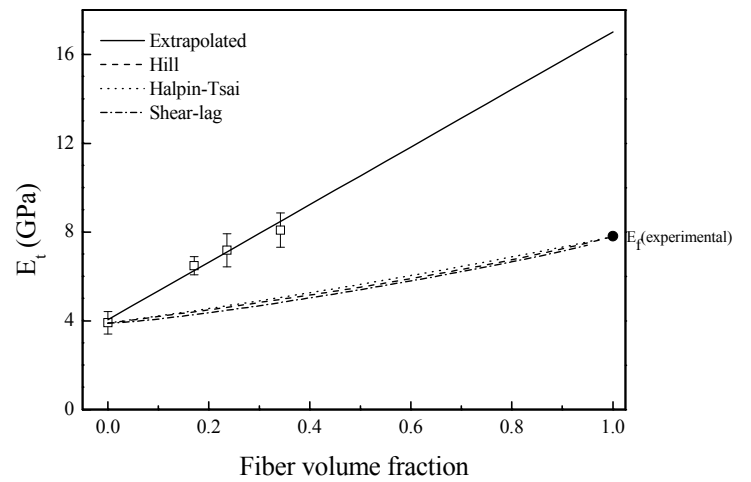

(c)

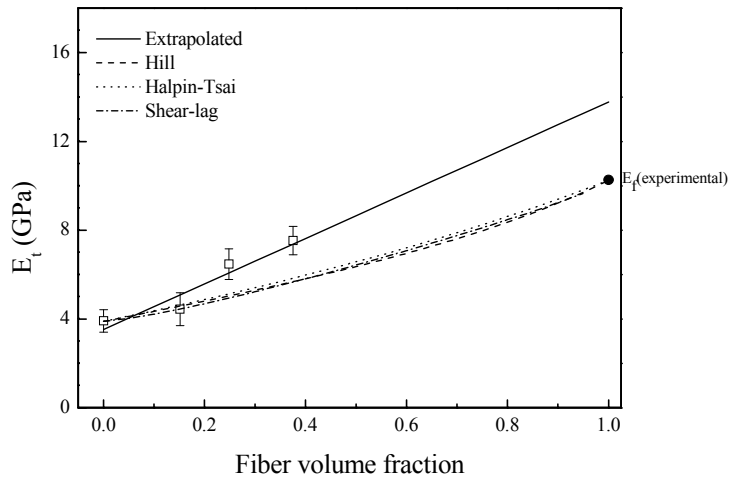

(b)

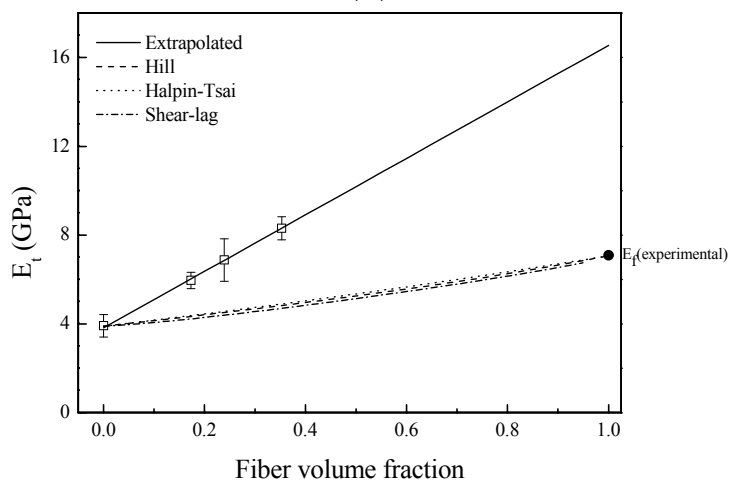

(d)

Figure 5. Estimation of composite modulus values using fiber experimental Young modulus values: (a) untreated; (b) silane; (c) $\mathrm{NaOH}$; and (d) $\mathrm{NaOH}+$ silane.

For composites based on untreated sisal fibers and PLA matrix, the correlation between theoretical and experimental values was good, whereas for composites based on silane treated fibers, the correlation between theoretical and experimental values was not very good. The experimental Young modulus values of composites based on alkali and $\mathrm{NaOH}+$ silane treated fibers were considerably much higher than theoretical ones, and it was decided to fit the experimental Young modulus values of composites to a straight line. At fiber volume fraction of one, which means that there would not be a matrix, the extrapolated fiber modulus values, $E_{\mathrm{f}}$ (extrapolated), were obtained and reported in Table 4. In composites based on untreated sisal fibers, no difference between the extrapolated and experimental modulus values was observed. However, in composites based on treated sisal fibers, especially in alkali and $\mathrm{NaOH}+$ silane treated fibers, significant differences can be observed. Although alkali treatment removed non-cellulosic constituents and increased the cellulose fraction of sisal fibers [5], it was observed that the obtained tensile properties of alkali and $\mathrm{NaOH}+$ silane treated fibers were lower than untreated ones, suggesting that alkali treatment could create voids in the fiber structure [3,5]. The schematic drawing of the hypothetical effect of alkali treatment on fiber structure is shown in Figure 6. 


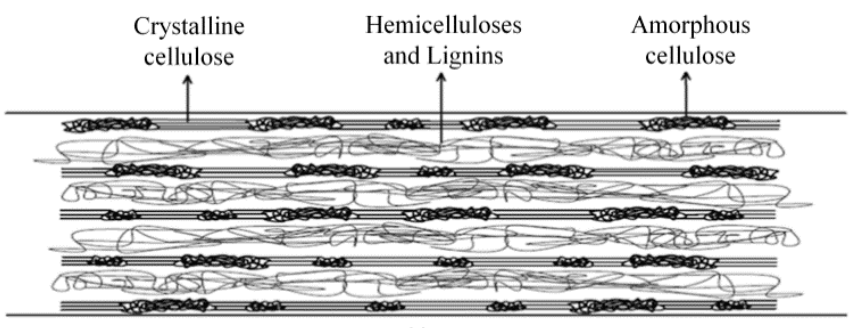

(a)

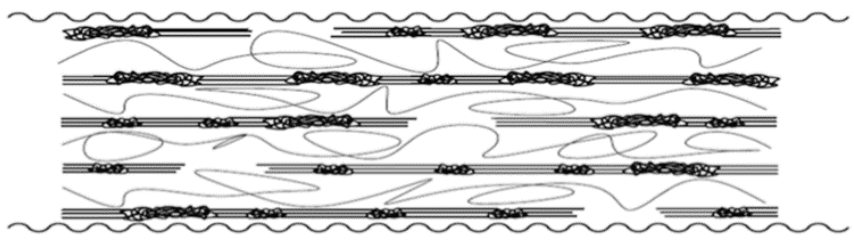

(b)

Figure 6. Schematic illustration showing the hypothetical effect of alkali treatment on the sisal fiber structure: (a) untreated fiber; and (b) alkali treated fiber.

It seemed that the created voids were responsible for obtaining the lowest Young modulus values determined by tensile test. However, previous work suggested that these voids could be filled during the injection process with melted PLA, improving fiber/PLA mechanical interlocking adhesion [5]. On the other hand, as the cellulose fraction in alkali and $\mathrm{NaOH}+$ silane treated fibers was higher than in untreated fibers ones, composites based on these fibers showed the highest values of tensile modulus, as observed in Figure 7a-d. In summary, experimental fiber tensile modulus values used for composites prediction were suitable for untreated fibers and to a lesser extent for silane treated fibers. However, experimental tensile moduli used for alkali and $\mathrm{NaOH}+$ silane fibers were not suitable for predicting the composites modulus values because the experimental composite modulus values were significantly higher than estimated ones. Alkali treatment removed hemicelluloses and lignins from sisal fiber, leading to creation of voids in fiber structure. Therefore, the moduli values estimated for composites were for composites with fibers that had internal voids. Nevertheless, during the injection molding process, because high injection pressure was applied, melted PLA can flow inside these voids. As a result, obtained experimental composite modulus values were significantly higher than estimated ones. Therefore, the $E_{\mathrm{f}}$ (extrapolated) values of alkali and $\mathrm{NaOH}+$ silane treated fibers are more accurate for composite modulus prediction than values determined by tensile test (Figure 7c,d).

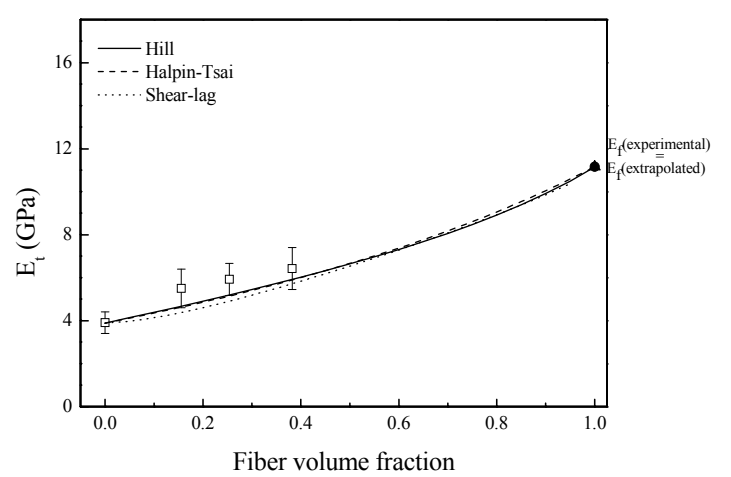

(a)

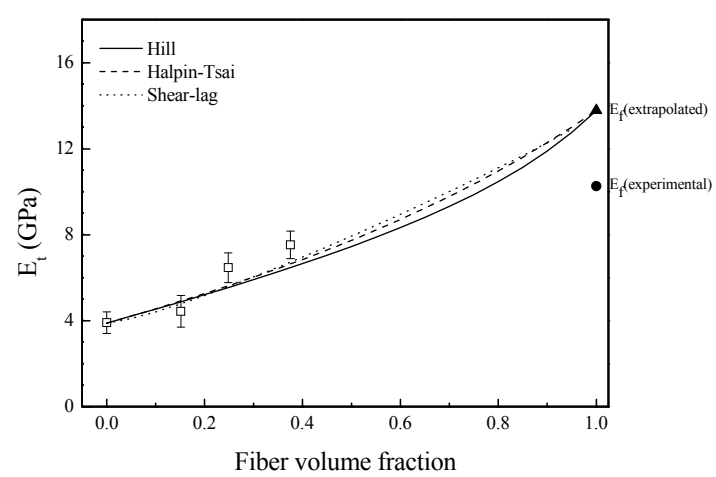

(b)

Figure 7. Cont. 


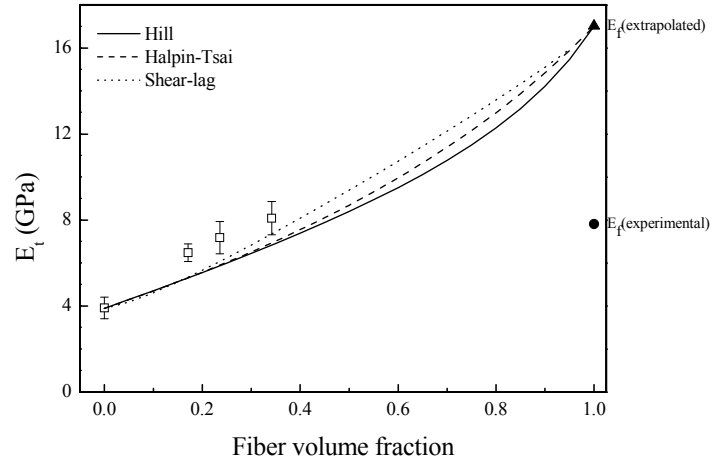

(c)

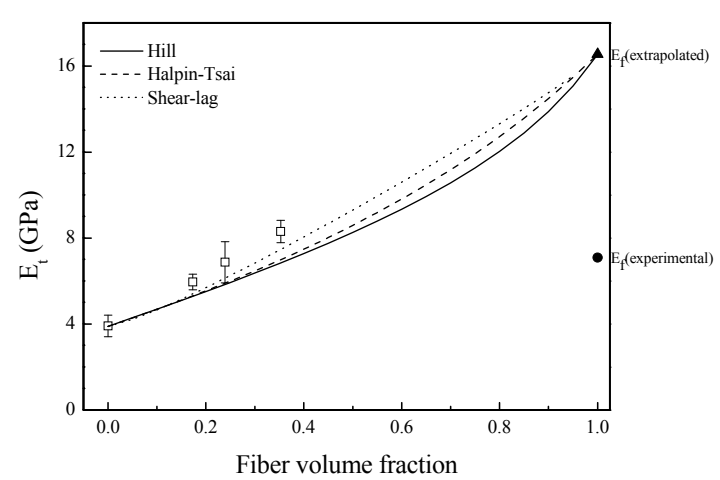

(d)

Figure 7. Determination of composite modulus values with extrapolated Young modulus values of untreated and treated sisal fibers: (a) untreated; (b) silane; (c) $\mathrm{NaOH}$; and (d) $\mathrm{NaOH}+$ silane.

\section{Conclusions}

All fiber surface treatments delayed the water absorption for a short period of time. For this reason, there was not a big difference in composites' water uptake profiles after different surface treatments. However, the diffusion coefficients of composites based on $\mathrm{NaOH}+$ silane treated sisal fibers were reduced considerably, suggesting that this treatment seemed to be the most effective treatment to reduce the water diffusion rate into the composites. Regarding the mechanical properties, tensile strength and Young modulus values of composites after the water uptake period were decreased due to the loss of sisal fiber/PLA adhesion as observed in SEM images. Experimental fiber tensile modulus values used for composite prediction were suitable for untreated, and, to a lesser extent, for silane treated fibers. However, experimental tensile moduli used for alkali and $\mathrm{NaOH}+$ silane fibers were not suitable for predicting the composite moduli. Nevertheless, $E_{\mathrm{f}}$ (extrapolated) values of alkali and $\mathrm{NaOH}+$ silane treated fibers are more accurate for composite modulus prediction than values determined by tensile test.

Acknowledgments: The authors are grateful for the financial support from the Basque Country Government in the frame of Consolidated Groups (IT-776-13) and Elkartek 2015 FORPLA3D project. Technical and human support provided by SGIker (Universidad del País Vasco-Euskal Herriko Unibertsitatea (UPV/EHU), Ministerio de Economía y Competitividad (MINECO), Gobierno Vasco-Eusko Jaurlaritza (GV/EJ), European Regional Development Fund (ERDF) and European Science Foundation (ESF)) is also gratefully acknowledged.

Author Contributions: Aitor Arbelaiz supervised the entire project along with Arantxa Eceiza. Ander Orue performed the experiments with the help of Cristina Peña-Rodriguez; Ander Orue and Aitor Arbelaiz analyzed the data and wrote the manuscript.

Conflicts of Interest: The authors declare no conflict of interest.

\section{References}

1. Arbelaiz, A.B.; Fernández, B.; Ramos, J.A.; Retegi, A.; Llano-Ponte, R.; Mondragon, I. Mechanical properties of short flax fibre bundle/polypropylene composites: Influence of matrix/fibre modification, fibre content, water uptake and recycling. Compos. Sci. Technol. 2006, 65, 1582-1592. [CrossRef]

2. Cantero, G.; Arbelaiz, A.; Mugika, F.; Valea, A.; Mondragon, I. Mechanical behaviour of wood/polypropylene composites: Effects of fibre treatments and ageing processes. J. Reinf. Plast. Comp. 2003, 22, 37-50. [CrossRef]

3. Orue, A.; Jauregi, A.; Peña-Rodriguez, C.; Labidi, J.; Eceiza, A.; Arbelaiz, A. The effect of surface modifications on sisal fiber properties and sisal/poly (lactic acid) interface adhesion. Compos. Part B Eng. 2015, 73, 132-138. [CrossRef]

4. Raj, G.; Balnois, E.; Baley, C.; Grohens, Y. Role of Polysaccharides on Mechanical and Adhesion Properties of Flax Fibres in Flax/PLA Biocomposite. Int. J. Polym. Sci. 2011, 2011, 1-11. [CrossRef] 
5. Orue, A.; Jauregi, A.; Unsuain, U.; Labidi, J.; Eceiza, A.; Arbelaiz, A. The effect of alkaline and silane treatments on mechanical properties and breakage of sisal fibers and poly(lactic acid)/sisal fiber composites. Compos. Part A Appl. Sci. Manuf. 2016, 84, 186-195. [CrossRef]

6. Arbelaiz, A.; Cantero, G.; Fernández, B.; Mondragon, I.; Gañán, P.; Kenny, J.M. Flax fiber surface modifications: Effects on fiber physico mechanical and flax/polypropylene interface properties. Polym. Compos. 2005, 26, 324-332. [CrossRef]

7. Fernandes, E.M.; Mano, J.F.; Reis, R.L. Hybrid cork-polymer composites containing sisal fibre: Morphology, effect of the fibre treatment on the mechanical properties and tensile failure prediction. Compos. Struct. 2013, 105, 153-162. [CrossRef]

8. Zou, H.; Wang, L.; Gan, H.; Yi, C. Effect of fiber surface treatments on the properties of short sisal fiber/poly(lactic acid) biocomposites. Polym. Compos. 2012, 33, 1659-1666. [CrossRef]

9. Aziz, S.H.; Ansell, M.P. The effect of alkalization and fibre alignment on the mechanical and thermal properties of kenaf and hemp bast fibre composites: Part 1-polyester resin matrix. Compos. Sci. Technol. 2004, 64, 1219-1230. [CrossRef]

10. Demir, H.; Atikler, U.; Balköse, D.; Tihmınlığlu, F. The effect of fiber surface treatments on the tensile and water sorption properties of polypropylene-luffa fiber composites. Compos. Part A Appl. Sci. Manuf. 2006, 37, 447-456. [CrossRef]

11. Abdelmouleh, M.; Boufi, S.; Belgacem, M.N.; Dufresne, A. Short natural-fibre reinforced polyethylene and natural rubber composites: Effect of silane coupling agents and fibres loading. Compos. Sci. Technol. 2007, 67, 1627-1639. [CrossRef]

12. Rong, M.Z.; Zhang, M.Q.; Liu, Y.; Yang, G.C.; Zeng, H.M. The effect of fiber treatment on the mechanical properties ofunidirectional sisal-reinforced epoxy composites. Compos. Sci. Technol. 2001, 61, 1437-1447. [CrossRef]

13. Huda, M.S.; Drzal, L.T.; Mohanty, A.K.; Misra, M. Effect of fiber surface-treatments on the properties of laminated biocomposites from poly(lactic acid) (PLA) and kenaf fibers. Compos. Sci. Technol. 2004, 68, 424-432. [CrossRef]

14. Rajesh, G.; Ratna Prasad, A.V.; Gupta, A.V.S. Mechanical and degradation properties of successive alkali treated completely biodegradable sisal fiber reinforced poly lactic acid composites. J. Reinf. Plast. Compos. 2015, 34, 951-961. [CrossRef]

15. Jiang, A.; Xi, J.; Wu, H. Effect of surface treatment on the morphology of sisal fibers in sisal/polylactic acid composites. J. Reinf. Plast. Compos. 2012, 31, 621-630. [CrossRef]

16. Joseph, P.V.; Rabello, M.S.; Mattoso, L.H.C.; Joseph, K.; Thomas, S. Environmental effects on the degradation behaviour of sisal fibre reinforced polypropylene composites. Compos. Sci. Technol. 2002, 62, 1357-1372. [CrossRef]

17. Karad, S.K.; Jones, F.R.; Attwood, D. Moisture absorption by cyanate ester modified epoxy resin matrices. Part I. Effect of spiking parameters. Polymer 2002, 43, 5209-5218. [CrossRef]

18. Facca, A.G.; Kortschot, M.T.; Yan, N. Predicting the elastic modulus of natural fibre reinforced thermoplastics. Compos. Part A Appl. Sci. Manuf. 2006, 37, 1660-1671. [CrossRef]

19. Hill, R. Elastic properties of reinforced solids: Some theoretical principles. J. Mech. Phys. Solids 1963, 11, 357-372. [CrossRef]

20. Halpin, J.C.; Tsai, S.W. Environmental Factors in Composite Materials Design. In U.S. Air Force Technical Report; Air Force Materials Laboratory: Wright-Patterson Air Force Base, OH, USA, 1967; pp. 67-423.

21. Cox, H.L. The elasticity and strength of paper and other fibrous materials. Br. J. Appl. Phys. 1952, 3, 72-79. [CrossRef]

22. Nairn, J.A. On the use of shear-lag methods for analysis of stress transfer in unidirectional composites. Mech. Mater. 1997, 26, 63-80. [CrossRef]

23. Sun, Z.; Zhao, X.; Wang, X.; Ma, J. Predicting the elastic properties of sisal fiber reinforced polypropylene composites by a new method based on generalized method of cells and laminate analogy approach. Compos. Sci. Technol. 2014, 91, 45-49. [CrossRef]

24. Jamshidian, M.; Tehrany, E.A.; Imran, M.; Jacquot, M.; Desobry, S. Poly-Lactic Acid: Production, applications, nanocomposites, and release studies. Compr. Rev. Food Sci. Food Saf. 2010, 9, 552-571. [CrossRef]

25. Pothan, L.A.; Thomas, S. Effect of hybridization and chemical modification on the water-absorption behavior of banana fiber-reinforced polyester composites. J. Appl. Polym. Sci. 2004, 91, 3856-3865. [CrossRef] 
26. Bourmaud, A.; Riviere, J.; Le Duigou, A.; Raj, G.; Baley, C. Investigations of the use a mussel-inspired compatibilizer to improve the matrix-fiber adhesion of a biocomposite. Poly. Test. 2009, 28, 668-672. [CrossRef]

27. George, J.; Bhagawan, S.S.; Thomas, S. Effects of environment on the properties of low-density polyethylene composites reinforced with pineapple-leaf fibre. Compos. Sci. Technol. 1998, 58, 1471-1485. [CrossRef]

28. Yew, G.H.; Yusof, A.M.M.; Ishak, Z.A.M.; Ishiaku, U.S. Water absorption and enzymatic degradation of poly (lactic acid)/rice starch composites. Polym. Degrad. Stab. 2005, 90, 488-500. [CrossRef]

29. Deroiné, M.; Le Duigou, A.; Corre, Y.; Le Gac, P.; Davies, P.; César, G.; Bruzaud, S. Accelerated ageing of polylactide in aqueous environments: Comparative study between distilled water and seawater. Polym. Degrad. Stab. 2014, 108, 319-329. [CrossRef]

30. Le Duigou, A.; Bourmaud, A.; Davies, P.; Baley, C. Long term immersion in natural seawater of Flax/PLA biocomposite. Ocean. Eng. 2014, 90, 140-148. [CrossRef]

31. Espert, A.; Vilaplana, F.; Karlsson, S. Comparison of water absorption in natural cellulosic fibres from wood and one-year crops in polypropylene composites and its influence on their mechanical properties. Compos. Part A Appl. Sci. Manuf. 2004, 35, 1267-1276. [CrossRef]

32. Hammiche, D.; Boukerrou, A.; Djidjelli, H.; Corre, Y.M.; Grohens, Y.; Pillin, I. Hydrothermal ageing of alfa fiber reinforced polyvinylchloride composites. Constr. Build. Mater. 2013, 47, 293-300. [CrossRef]

33. Islam, M.S.; Pickering, K.L.; Foreman, N.J. Influence of hygrothermal ageing on the physico-mechanical properties of alkali treated industrial hemp fibre reinforced polylactic acid composites. J. Polym. Environ. 2010, 18, 696-704. [CrossRef]

(C) 2016 by the authors; licensee MDPI, Basel, Switzerland. This article is an open access article distributed under the terms and conditions of the Creative Commons Attribution (CC-BY) license (http://creativecommons.org/licenses/by/4.0/). 